\title{
Residual de herbicidas aplicados na soja sobre o milho safrinha e controle de Digitaria insularis ${ }^{1}$
}

\author{
Danilo Neiva de Andrade 2 , Túlio Porto Gonçalo², Eugenio Miranda Sperandio ${ }^{3}$, Renata Pereira \\ Marques $^{3}$
}

\begin{abstract}
Resumo: O manejo de plantas daninhas com associação de ingredientes ativos tem sido uma alternativa para contornar o problema de biótipos resistentes. Objetivou-se com este trabalho testar moléculas de herbicidas em isoladas e em associação aplicadas em pré-emergência na cultura da soja para o controle de $D$. insularis em um sistema convencional de produção e com histórico de alta incidência dessa espécie, bem como a avaliação de residual dos herbicidas sobre a cultura do milho semeado em sucessão à soja. Os tratamentos foram: clomazona + carfentrazona etílica; diclosulam; s-metolacloro; trifluralina; imazetapir; sulfentrazona; imazetapir + flumioxazina e flumioxazina. Após 90 dias após a pulverização desses tratamentos, semeou-se a cultura do milho. Avaliou-se a porcentagem de controle das plantas daninhas presentes na área durante o ciclo da cultura da soja, a fitointoxicação e parâmetros biométricos para a cultura do milho. Os dados foram submetidos análise de variância pelo teste $\mathrm{F}$ e as médias comparadas pelo teste de Scott-Knott $(\mathrm{p} \leq 0,05)$. A mistura comercial de imazetapir + flumioxazina foi eficaz no controle de $D$. insularis e de outras espécies daninhas monocotiledôneas ou eudicotiledôneas, com residual observado 35 dias após a aplicação. Os tratamentos não causaram injúrias sobre o estande, altura de plantas e produtividade de grãos do milho.
\end{abstract}

Palavras-chave: Capim amargoso; Pré-emergência; Zea mays; Fitointoxicação.

\section{Carryover effects of herbicides on corn planted right after soybean and control of Digitaria insularis}

\begin{abstract}
Weed management with the association of active ingredients has been an alternative to overcome the problem of resistant biotypes. The objective of this work was to test herbicide molecules in isolates and in association applied in pre-emergence in soybean culture to control $D$. insularis in a conventional production system and with a history of a high incidence of this species, as well as the evaluation of residual herbicides on maize sown in succession to soybean. The treatments were: clomazone + ethyl carfentrazone; diclosulam; s-metolachlor; trifluralin; imazetapyr; sulfentrazone; imazetapyr + flumioxazin and flumioxazin. After 90 days after spraying these treatments, corn was sown. The percentage of weed control present in the area during the soybean crop cycle, phytointoxication and biometric parameters for the corn crop was evaluated. The data were submitted to analysis of variance by the $\mathrm{F}$ test and the means compared by the Scott-Knott test $(\mathrm{p} \leq 0,05)$. The commercial mixture of imazetapyr + flumioxazin was effective in controlling $D$. insularis and other monocotyledonous or eudicotyledonous weeds, with residual observed 35 days after application. The treatments did not cause injury to the stand, plant height, and out-of-season corn grain yield.
\end{abstract}

Keywords: Sourgrass; Pre-emergent; Zea mays; Phytoxication.

\footnotetext{
${ }^{1}$ Submetido em 05/12/2019 e aprovado em 24/07/2020;

2 Grupo Associado de Pesquisa do Sudoeste Goiano, Rio Verde, GO , Brasil. E-mail: danillo.neiva@gapescna.agr.br - ORICD: https://orcid.org/0000-0002-2599-2750; tulio.goncalo@gapescna.agr.br - ORICD: https://orcid.org/0000-0003-4464-6914;

${ }^{3}$ Instituto Federal Goiano, Polo de Inovação, Rio Verde, GO, Brasil. E-mail: eugeniosperandio@ gmail.com - ORICD: https://orcid.org/00000002-7761-7186; renata.marques@ifgoiano.edu.br (Autor correspondente) - ORICD: https://orcid.org/0000-0002-8933-6306
} 


\section{Introdução}

O milho (Zea mays) é uma das principais culturas produzidas mundialmente e faz parte do grupo dos cereais que constituem a base da alimentação mundial. No Brasil, o seu cultivo é realizado em duas épocas: primeira safra, ou safra de verão, e o de segunda safra, conhecido também como milho safrinha. Com uma área plantada de 16,75 milhões de hectares e produção estimada em 95,25 milhões de toneladas, a produção brasileira de milho é a terceira maior do mundo (CONAB, 2019).

Entre os entraves para o aumento da produtividade destacam-se os estresses bióticos como, por exemplo, a competição com plantas daninhas. Quando se estabelecem na lavoura, as plantas daninhas competem por água, luz, espaço e nutrientes com a cultura de interesse (Gazola et al., 2016). Dentre as plantas daninhas de importância econômica, as espécies do gênero Digitaria são umas das mais estudadas. Existem mais de 300 espécies pertencentes a este gênero no mundo (Canto-Dorow, 2001). No Brasil 38 espécies são encontradas, 26 nativas e 12 introduzidas.

O capim amargoso (Digitaria insularis [L.] Fedde) é nativo das Américas, com ocorrência dos Estados Unidos até o sul do continente na Argentina. Entretanto, D. insularis encontra-se amplamente disseminado nas principais áreas agrícolas do mundo (CABI, 2019), sendo especialmente problemáticas no centro-oeste brasileiro em áreas que realizam a sucessão sojamilho. A sua dispersão é feita principalmente por sementes leves e com pilosidades, fato que permite sua disseminação a longas distâncias. Essa é uma espécie de ciclo perene, podendo formar touceiras e rizomas, que a torna mais tolerante as condições de sombreamento realizada pela cultura (Gazola et al., 2016; CABI, 2019).

O manejo do capim amargoso se baseia em métodos culturais, físicos e, principalmente químicos. O uso de herbicidas no controle de plantas daninhas é o método mais empregado. Estes podem ser categorizados de acordo com a sua seletividade, divididos em seletivos e não seletivos; quanto à translocação, com ação de contato ou de ação sistêmica; quanto à época de aplicação, onde os herbicidas são aplicados préplantio, pré-emergência e pós-emergência (Gazola et al., 2016). O sucesso do controle químico depende, entre outras coisas, da cultura com a qual $D$. insularis irá competir, da tecnologia de aplicação e do princípio ativo do produto. Todavia, o uso indiscriminado de herbicidas, aliado à não utilização de outros métodos de controle proporciona o desenvolvimento de populações de indivíduos resistentes, como relatado em muitas partes do mundo e inclusive no Brasil (Han et al., 2017; Heap, 2019).

Nesse sentido, devido aos insucessos no controle dessa espécie, em pós-emergência, principalmente com glifosato e cletodim, a adoção de herbicidas em pré-emergência é uma alternativa viável, e se destaca por evitar a competição precoce entre a cultura de interesse e as plantas daninhas, à medida que estas últimas vão emergindo, pois muitas espécies de daninhas possuem maior potencial de crescimento do que o milho. Outra vantagem é a capacidade de controlar as plantas daninhas nos seus estágios iniciais de desenvolvimento, na qual a planta está mais suscetível a ação dos princípios ativos, comprometendo a germinação de sementes e o desenvolvimento das espécies de daninhas (Awan, et al., 2015, Muniz et al., 2019). Entretanto, quando se opta por utilizar herbicidas em pré-emergência, isolado ou em associações, deve-se considerar que a eficiência no controle de plantas daninhas é influenciada tanto pelas propriedades físico-químicas do solo quanto climáticas. Pois, os herbicidas podem não ser completamente degradados durante o ciclo da cultura principal e deixar um residual que pode ser prejudicial a cultura sucessora (Awan et al., 2016; Pino et al., 2016).

Objetivou-se com esta pesquisa testar moléculas de herbicidas em isoladas e em associação aplicadas em pré-emergência na cultura da soja para o controle de $D$. insularis em um sistema convencional de produção e com histórico de alta incidência dessa espécie, bem como a avaliação de residual dos herbicidas sobre a cultura do milho semeado em sucessão à soja.

\section{Material e Métodos}

\subsection{Caracterização da área experimental}

O experimento foi conduzido em área de produção comercial de milho e soja $\left(17^{\circ} 49^{\prime} 01^{\prime \prime}\right.$ $\mathrm{S}, 51^{\circ} 03$ ' 28" W e, $752 \mathrm{~m}$ de altura) em Rio Verde-GO, cujo solo possui $18 \%$ de argila, 7,5\% de silte e $74,5 \%$ de areia, sendo que na safra 
2016/17, a mesma permaneceu em pousio. A escolha dessa área foi baseada nos altos níveis infestação por Digitaria insularis (capimamargoso) e ausência de controle da espécie com o herbicida glifosato. Os dados de precipitação pluvial média da área experimental durante o período de condução do estudo encontram-se na Figura 1.

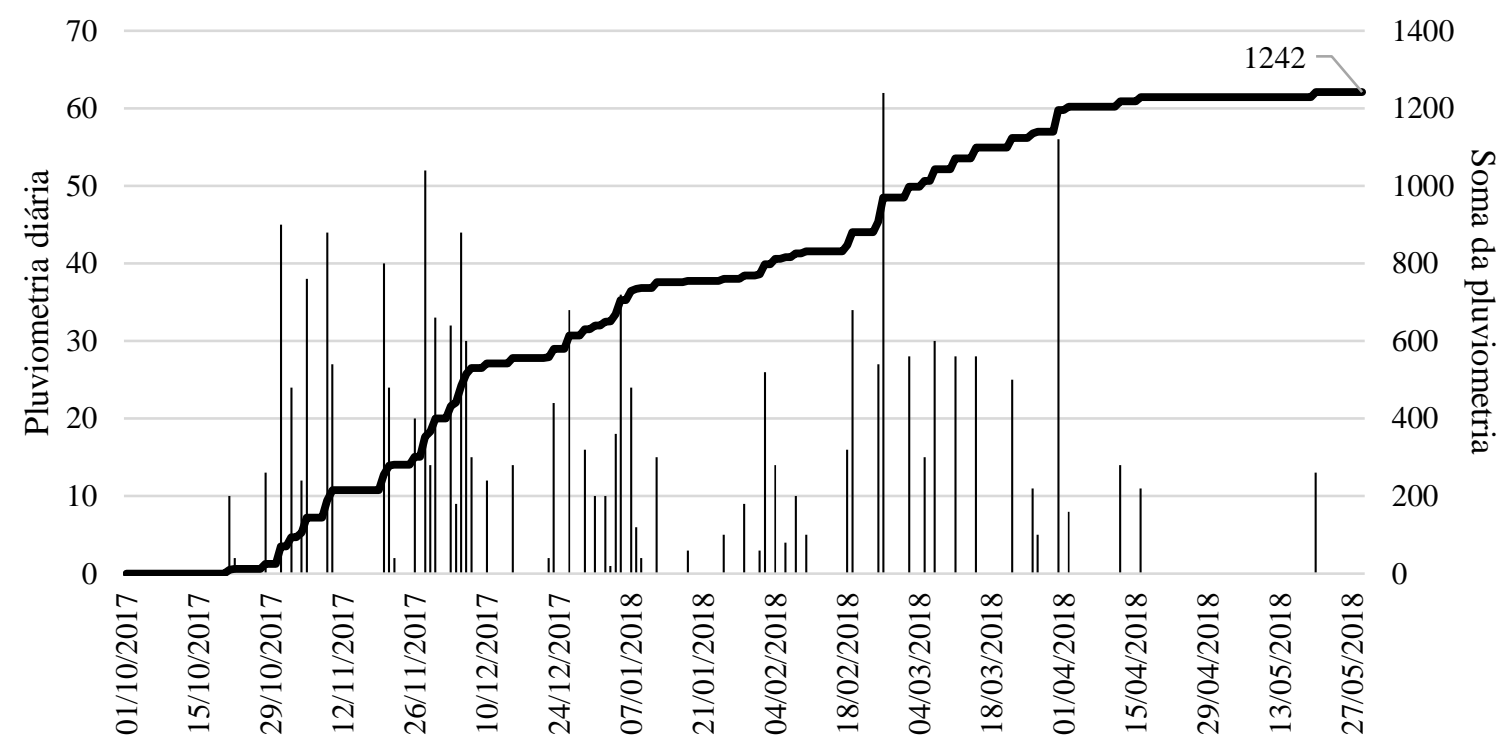

Figura 1 Precipitação pluviométrica no local do experimento durante os meses de condução em Rio Verde-GO.

\subsection{Preparo da área experimental}

Antes da instalação do experimento realizou-se dessecação em área total, com o herbicida paraquate $\left(400 \mathrm{~g}\right.$ i. a. $\left.\mathrm{ha}^{-1}\right)$ e posterior gradagem. Após este procedimento, realizou-se a pulverização dos tratamentos em pré-emergência, na modalidade plante e aplique, em delineamento em blocos casualizados (DBC), com 9 tratamentos e 4 repetições, conforme a Tabela $1 \mathrm{e}$ semeou-se a soja. Para a pulverização dos tratamentos foi utilizado um pulverizador costal pressurizado a $\mathrm{CO}_{2}$, com vazão de $150 \mathrm{~L} \mathrm{ha}^{-1}$, pressão de 3 bar. No momento da pulverização a velocidade do vento era de $5 \mathrm{~km}$ por hora, a umidade do ar de $80 \%$ e a temperatura média de $28^{\circ} \mathrm{C}$

Tabela 1 Tratamentos químicos em pré-emergência para o manejo de $D$. insularis

\begin{tabular}{cll}
\hline Tratamento & \multicolumn{1}{c}{ Ingrediente Ativo } & Dose i.a. aplicada $(\mathrm{g})$ \\
\hline 1 & Paraquate* & 400 \\
2 & Paraquate + clomazona + carfentrazona etílica & $400+600+15$ \\
3 & Paraquate + diclosulam & $400+29,4$ \\
4 & Paraquate + s-metolacloro & $400+1.152$ \\
5 & Paraquate + trifluralina & $400+1.200$ \\
6 & Paraquate + imazetapir & $400+100$ \\
7 & Paraquate + sulfentrazona & $400+250$ \\
8 & Paraquate + imazetapir + flumioxazina & $400+100+50$ \\
9 & Paraquate + flumioxazina & $400+50$ \\
\hline
\end{tabular}

Noventa dias após a pulverização dos tratamentos, dessecou-se a área com os herbicidas glifosato e cletodim (900 e 536,7 g e.a./i.a.ha ${ }^{-1}$, respectivamente). Para a pulverização dos tratamentos foi utilizado um pulverizador costal pressurizado a $\mathrm{CO}_{2}$, com vazão de $150 \mathrm{~L} \mathrm{ha}^{-1}$, pressão de 3 bar. Durante a pulverização a velocidade do vento foi de $6 \mathrm{~km}$ por hora, a umidade do ar de $78 \%$ e a temperatura média de $30^{\circ} \mathrm{C}$.

Em seguida, realizou-se a semeadura do milho híbrido P3646 com espaçamento de $0,5 \mathrm{~m}$ entrelinhas e população de 60 mil plantas por 
hectare, em sistema de produção convencional. As parcelas possuíam a dimensão de 3 x $5 \mathrm{~m}$. Durante o ciclo da cultura do milho, realizou-se os tratos culturais conforme a necessidade da cultura.

\subsection{Avaliações}

Aos 7, 14, 21, 28 e 35 dias após a aplicação (DAA) dos tratamentos, avaliou-se o número de plantas germinadas na área (monodicotiledôneas - Eleusine indica, Comellina sp. e D. horizontalis e eudicotiledôneas - Spermacoce latifolia e Ipomoea grandifolia) competindo com a cultura da soja. Para isso, utilizou um quadrado metálico $(50 \times 50 \mathrm{~cm})$ lançado aleatoriamente uma vez por parcela. Neste período as plantas encontradas dentro do quadrado foram quantificadas e identificadas.

Para esta avaliação, utilizou-se a metodologia do quadrado inventário (Erasmo et al. 2004). Após a contagem foi calculado a eficiência do tratamento comparado com o tratamento em que se havia sido aplicado somente o paraquate, conforme a fórmula de Abbott (1925):

$$
M a=\left(\frac{\mathrm{Mt}-\mathrm{Mc}}{100-\mathrm{Mc}}\right) \cdot 100
$$

onde que Ma $=$ Mortalidade corrigida em função do tratamento controle (Paraquate - 400g i.a. ha1), $\mathrm{Mt}=$ Mortalidade observada no tratamento com o herbicida e $\mathrm{Mc}=$ Mortalidade observada no tratamento controle.

Aos 7, 14, 21, 28 e 35 dias após a semeadura (DAS) do milho avaliou-se a porcentagem de fitointoxicação nas plantas de milho em função dos herbicidas pulverizados em pré-emergência.

Avaliou-se também estande inicial e final de plantas (plantas por hectare - contagem de 2 linhas de $5 \mathrm{~m}$ ), altura de planta (V3), peso de 1000 grãos e a produtividade $\left(\mathrm{kg} \mathrm{ha}^{-1}\right)$. A colheita foi realizada a partir de plantas das duas fileiras centrais de cada parcela.

Os resultados foram submetidos à análise de variância pelo teste $\mathrm{F}$, e as médias dos tratamentos foram comparadas pelo teste de Scott-Knott ( $\mathrm{p} \leq$ $0,05)$.

\section{Resultados e Discussão}

Na Tabela 2 encontra-se a análise de variância para os testes de controle por de herbicidas em pré-emergência nas espécies de plantas daninhas estudadas.

Tabela 2 Resumo da análise de variância para os testes de fitointoxicação aos 7, 14, 21, 28 e 35 dias após a aplicação (DAA) de herbicidas pré-emergência

\begin{tabular}{|c|c|c|c|c|c|}
\hline \multirow{2}{*}{ ANOVA } & $7 \mathrm{DAA}$ & 14 DAA & $21 \mathrm{DAA}$ & $28 \mathrm{DAA}$ & 35 DAA \\
\hline & \multicolumn{5}{|c|}{ Capim amargoso } \\
\hline Valor de F & $57,67 * *$ & $133,91 * *$ & $107,84 * *$ & $66,63 * *$ & $81,15^{* *}$ \\
\hline C.V. $(\%)$ & 13,86 & 7,64 & 10,46 & 16,21 & 16,31 \\
\hline \multirow[t]{2}{*}{ E.P. } & 3,54 & 2,14 & 2,39 & 3,18 & 2,55 \\
\hline & \multicolumn{5}{|c|}{ Eudicotiledônea } \\
\hline Valor de F & $45,82 * *$ & $57,03 * *$ & $149,56 * *$ & $70,69 * *$ & $545,1 * *$ \\
\hline C.V. $(\%)$ & 20,24 & 22,89 & 16,72 & 37,15 & 23,44 \\
\hline \multirow[t]{2}{*}{ E.P. } & 5,18 & 4,48 & 2,88 & 3,65 & 0,95 \\
\hline & \multicolumn{5}{|c|}{ Monocotiledônea } \\
\hline Valor de F & $154,38 * *$ & $282,54 * *$ & $508,06 * *$ & $303,04 * *$ & $101,07 * *$ \\
\hline C.V. $(\%)$ & 6,1 & 4,82 & 3,55 & 7,74 & 23,04 \\
\hline E.P. & 1,52 & 1,72 & 1,19 & 1,71 & 2,6 \\
\hline
\end{tabular}

CV: Coeficiente de variação. EP: Erro padrão. **Significativo a 1\% de probabilidade pelo teste F.

A ausência de palhada permitiu observar o potencial máximo dos herbicidas utilizados. A presença de restos culturais na superfície do solo pode dificultar a germinação e emergência de algumas espécies de plantas daninha devido à liberação de compostos alelopáticos no processo de decomposição, além de funcionar como barreira física, impedindo a emergência de sementes de plantas daninhas, especialmente aquelas que possuem pequenas quantidades de reserva. Entretanto, a palhada pode diminuir o contato de herbicidas residuais com os seus alvos, comprometendo a sua capacidade e, consequentemente, diminuindo a percentagem de controle (Dorn et al., 2013). 
$\mathrm{Na}$ primeira e nas demais avaliações do controle de capim-amargoso, a mistura imazetapir e flumioxazina apresentou os melhores resultados, persistindo até os 35 DAA, controlando mais de $75,7 \%$ da emergência de $D$. insularis no último dia de avaliação (Tabela 3). Essa persistência pode auxiliar quando se trata de manejo em pré-emergência pois, levando em consideração a cultura da soja, após esse período, apresenta capacidade de, por si só, controlar as plantas daninhas que emergirem devido ao fechamento das entre linhas (Spadotto et al., 2017).

Tabela 3 Média percentual de controle de capim-amargoso aos 7, 14, 21 e 35 dias após a aplicação (DAA) de herbicidas em pré-emergência

\begin{tabular}{|c|c|c|c|c|c|}
\hline Ingrediente Ativo & 7 DAA & 14 DAA & 21 DAA & 28 DAA & 35 DAA \\
\hline $\begin{array}{l}\text { Clomazona }+ \\
\text { carfentrazona etílica }\end{array}$ & $57,3 \pm 8,97 \mathrm{c}$ & $58,9 \pm 2,96 \mathrm{c}$ & $46,6 \pm 6,62 \mathrm{~d}$ & $31,6 \pm 6,33 \mathrm{~d}$ & $26,4 \pm 9,37 \mathrm{~d}$ \\
\hline Diclosulam & $72,9 \pm 6,28 b$ & $70,2 \pm 1,34 b$ & $69,4 \pm 1,75 b$ & $70,7 \pm 3,72 b$ & $55,8 \pm 4,01 \mathrm{~b}$ \\
\hline S-metolacloro & $59,5 \pm 6,31 \mathrm{c}$ & $62,5 \pm 7,28 \mathrm{c}$ & $56,7 \pm 3,87 \mathrm{c}$ & $48,3 \pm 3,07 \mathrm{c}$ & $40,7 \pm 7,01 \mathrm{c}$ \\
\hline Trifluralina & $52,7 \pm 2,13 \mathrm{c}$ & $66,5 \pm 4,16 b$ & $38,9 \pm 3,01 \mathrm{e}$ & $27,1 \pm 9,75 \mathrm{e}$ & $23,5 \pm 9,75 \mathrm{~d}$ \\
\hline Imazetapir & $58,0 \pm 7,61 \mathrm{c}$ & $58,0 \pm 2,59 \mathrm{c}$ & $39,9 \pm 10,02 \mathrm{e}$ & $33,7 \pm 16,45 \mathrm{~d}$ & $15,6 \pm 12,66 \mathrm{e}$ \\
\hline Sulfentrazona & $32,4 \pm 13,32 \mathrm{~d}$ & $49,3 \pm 6,33 d$ & $40,9 \pm 4,56 \mathrm{e}$ & $35,1 \pm 6,33 \mathrm{~d}$ & $28,1 \pm 4,62 \mathrm{~d}$ \\
\hline $\begin{array}{l}\text { Imazetapir }+ \\
\text { flumioxazina }\end{array}$ & $94,5 \pm 4,54 \mathrm{a}$ & $92,2 \pm 1,47$ a & $88,2 \pm 4,20 \mathrm{a}$ & $86,0 \pm 4,40 \mathrm{a}$ & $75,7 \pm 7,56 \mathrm{a}$ \\
\hline Flumioxazina & $33,3 \pm 8,83 \mathrm{~d}$ & $47,8 \pm 6,47 \mathrm{~d}$ & $30,2 \pm 5,58 \mathrm{f}$ & $20,8 \pm 7,53 \mathrm{e}$ & $15,7 \pm 10,12 \mathrm{e}$ \\
\hline
\end{tabular}

*Em todos os tratamentos foi utilizado o herbicida Paraquate como padrão. Médias seguidas pela mesma letra em coluna não diferem entre si pelo teste Scott-Knott, a $1 \%$ de probabilidade.

Para as eudicotiledôneas, os melhores resultados de controle ocorreram com os tratamentos-metolocloro, imazetapir + flumioxazina e flumioxazina isolado, aos 7 e 14 DAA (Tabela 4). Nos demais dias avaliados, apenas s-metolocloro, imazetapir + flumioxazina diferiram do controle, com a mistura apresentando maiores porcentagens de controle. Com os presentes resultados pode-se observar que a mistura dos herbicidas flumioxazina + imazetapir apresenta melhores resultados de controle quando aplicados de forma juntos do que quando aplicados isoladamente, aumentando assim a capacidade de controle de plantas daninhas, quando comparado com aplicação dos herbicidas isolados para o controle de espécies eudicotiledôneas. Isso demonstra que a interação entre diferentes moléculas é importante para a obtenção do controle efetivo de plantas daninhas, muitas vezes apresentando melhores do que aqueles quando esses princípios ativos são aplicados separadamente (Pazuch et al., 2017; Spadotto et al., 2017), como demonstrado no presente trabalho.

Tabela 4 Média percentual de controle de espécie eudicotiledôneas sem presença de palha, avaliada aos 7, 14, 21 e 35 dias após a aplicação (DAA) de herbicidas pré-emergência

\begin{tabular}{lccccc}
\hline \multicolumn{1}{c}{ Ingrediente Ativo } & 7 DAA & 14 DAA & $21 \mathrm{DAA}$ & $28 \mathrm{DAA}$ & $35 \mathrm{DAA}$ \\
\hline Clomazona + & $44,1 \pm 19,20 \mathrm{~b}$ & $22,9 \pm 17,66 \mathrm{c}$ & $9,1 \pm 3,19 \mathrm{~d}$ & $0,0 \mathrm{c}$ & $0,0 \mathrm{c}$ \\
$\quad$ carfentrazona etílica & $54,8 \pm 19,63 \mathrm{~b}$ & $46,2 \pm 9,32 \mathrm{~b}$ & $25,6 \pm 12,65 \mathrm{c}$ & $0,0 \mathrm{c}$ & $0,0 \mathrm{c}$ \\
Diclosulam & $92,9 \pm 8,25 \mathrm{a}$ & $74,1 \pm 4,46 \mathrm{a}$ & $72,8 \pm 2,80 \mathrm{~b}$ & $39,9 \pm 21,64 \mathrm{~b}$ & $5,9 \pm 3,96 \mathrm{~b}$ \\
S-metolacloro & $36,9 \pm 7,14 \mathrm{~b}$ & $20,4 \pm 17,02 \mathrm{c}$ & $9,2 \pm 3,90 \mathrm{~d}$ & $0,0 \mathrm{c}$ & $0,0 \mathrm{c}$ \\
Trifluralina & $10,7 \pm 21,43 \mathrm{c}$ & $2,1 \pm 4,17 \mathrm{c}$ & $16,4 \pm 9,78 \mathrm{~d}$ & $0,0 \mathrm{c}$ & $0,0 \mathrm{c}$ \\
Imazetapir & $36,9 \pm 7,14 \mathrm{~b}$ & $20,4 \pm 17,02 \mathrm{c}$ & $9,1 \pm 3,19 \mathrm{~d}$ & $0,0 \mathrm{c}$ & $0,0 \mathrm{c}$ \\
Sulfentrazona & $92,3 \pm 8,99 \mathrm{a}$ & $74,1 \pm 4,46 \mathrm{a}$ & $84,9 \pm 3,01 \mathrm{a}$ & $72,8 \pm 3,76 \mathrm{a}$ & $66,9 \pm 3,82 \mathrm{a}$ \\
Imazetapir + & $92,3 \pm 8,99 \mathrm{a}$ & $91,9 \pm 5,99 \mathrm{a}$ & $83,5 \pm 5,26 \mathrm{a}$ & $64,4 \pm 4,32 \mathrm{a}$ & $0,0 \mathrm{c}$ \\
$\quad$ flumioxazina & Flumioxazina &
\end{tabular}

*Em todos os tratamentos foi utilizado o herbicida Paraquate como padrão. Médias seguidas pela mesma letra em coluna não diferem entre si pelo teste Scott-Knott, a $1 \%$ de probabilidade. 
As espécies monocotiledôneas encontradas na área foram capim-colchão (Digitaria horizontalis), timbete (Cenchrus echinatus), capim pé de galinha (Eleusine indica) e trapoeraba (Comellina sp.). Houve diferença significativa nas avaliações realizadas nos 7DAA apenas no tratamento paraquate + flumioxazina que apresentou uma média de controle de 49,6\%. Os demais tratamentos nas primeiras avaliações obtiveram valores acima de $50 \%$ de controle (Tabela 5).

Tabela 5 Média percentual de controle de espécie monocotiledôneas sem presença de palha, avaliado aos 7, 14, 21 e 35 dias após a aplicação (DAA) de herbicidas pré-emergência

\begin{tabular}{lccccc}
\hline \multicolumn{1}{c}{ Ingrediente Ativo } & 7 DAA & 14 DAA & $21 \mathrm{DAA}$ & $28 \mathrm{DAA}$ & $35 \mathrm{DAA}$ \\
\hline Clomazona + & $56,9 \pm 9,08 \mathrm{a}$ & $80,7 \pm 2,06 \mathrm{~b}$ & $73,3 \pm 1,31 \mathrm{~d}$ & $40,6 \pm 1,58 \mathrm{e}$ & $9,2 \pm 7,38 \mathrm{~d}$ \\
$\quad$ carfentrazona etílica & $56,3 \pm 5,46 \mathrm{a}$ & $79,8 \pm 2,00 \mathrm{~b}$ & $75,8 \pm 2,30 \mathrm{c}$ & $50,8 \pm 4,58 \mathrm{~d}$ & $17,7 \pm 5,44 \mathrm{c}$ \\
Diclosulam & $58,6 \pm 8,00 \mathrm{a}$ & $92,1 \pm 1,87 \mathrm{a}$ & $82,4 \pm 1,34 \mathrm{~b}$ & $77,3 \pm 4,62 \mathrm{~b}$ & $54,5 \pm 7,26 \mathrm{~b}$ \\
S-metolacloro & $56,6 \pm 7,85 \mathrm{a}$ & $79,8 \pm 2,00 \mathrm{~b}$ & $72,7 \pm 1,68 \mathrm{~d}$ & $37,6 \pm 4,63 \mathrm{e}$ & $4,5 \pm 8,93 \mathrm{~d}$ \\
Trifluralina & $56,4 \pm 8,91 \mathrm{a}$ & $83,4 \pm 5,25 \mathrm{~b}$ & $78,2 \pm 2,18 \mathrm{c}$ & $62,3 \pm 2,21 \mathrm{c}$ & $44,3 \pm 7,87 \mathrm{~b}$ \\
Imazetapir & $55,6 \pm 7,70 \mathrm{a}$ & $78,9 \pm 2,95 \mathrm{~b}$ & $71,4 \pm 3,13 \mathrm{~d}$ & $36,6 \pm 5,44 \mathrm{e}$ & $4,7 \pm 5,51 \mathrm{~d}$ \\
Sulfentrazona & $58,7 \pm 6,86 \mathrm{a}$ & $93,9 \pm 1,71 \mathrm{a}$ & $93,4 \pm 2,19 \mathrm{a}$ & $87,8 \pm 1,49 \mathrm{a}$ & $68,6 \pm 5,52 \mathrm{a}$ \\
Imazetapir + & $49,6 \pm 8,48 \mathrm{~b}$ & $55,4 \pm 6,66 \mathrm{c}$ & $58,1 \pm 5,07 \mathrm{e}$ & $3,9 \pm 3,27 \mathrm{f}$ & $0,0 \pm 0,00 \mathrm{~d}$ \\
$\quad$ flumioxazina & Flumioxazina &
\end{tabular}

*Em todos os tratamentos foi utilizado o herbicida Paraquate como padrão. Médias seguidas pela mesma letra em coluna não diferem entre si pelo teste Scott-Knott, a $1 \%$ de probabilidade.

Aos 14 DAA, houve evolução no controle dos tratamentos, sendo os tratamentos com smetolacloro e imazetapir + flumioxazina apresentaram o melhor controle no período. A evolução do controle destes herbicidas pode ser devido a condições ambientais favoráveis, principalmente com o aumento da umidade. As avaliações realizadas aos 21 e 28 DAA apresentaram alto controle de plantas daninhas em alguns tratamentos, tais como s-metolacloro e imazetapir + flumioxazina. Os demais tratamentos, exceto flumioxazina, obtiveram valores de controles considerados razoáveis, mas com nível de controle abaixo de $80 \%$. A maioria dos herbicidas que apresentam atividade residual no solo, são bastante influenciados pelo $\mathrm{pH}$, teores de argila e quantidade de matéria orgânica do solo.

Aos 35 DAA o tratamento imazetapir + flumioxazina controlou $68,6 \%$ das plantas, indicando bom efeito residual para controle de espécies monocotiledôneas. Os tratamentos smetolacloro e imazetapir apresentaram níveis de controle diferentes, mas que não se diferiram estatisticamente (Tabela 5). No presente trabalho, o solo utilizado tinha o $\mathrm{pH}$ de $4,5\left(\mathrm{CaCl}_{2}\right)$ teor de argila de $18 \%$ e $21,3 \mathrm{~g} \mathrm{dm}^{-3}$ de matéria orgânica, o que justifica o percentual de controle dos tratamentos. Os herbicidas permanecem ativos por mais tempo em solos com altos teores de argila, matéria orgânica e baixo pH (Milanova \& Grigorov, 1996).

Não houve diferenças significativas para as variáveis analisadas: estande, altura de plantas e produtividade de grãos do milho safrinha (Tabela 6 e 7). Esse resultado demonstra que os tratamentos utilizados são extremamente seguros para serem utilizados na cultura da soja quando a cultura do milho for semeada em sucessão, desde que observados as condições em que esse ensaio foi conduzido: período de 90 dias para a semeadura da cultura sucessora, condições climáticas similares, textura do solo e o híbrido mais adequado. Em vários campos de cultivo, o milho tem sido muito utilizado como cultura sucessora da soja a fim de analisar o potencial de injúria de herbicidas residuais no manejo de plantas daninhas. Alguns trabalhos verificaram que o milho é sensível ao imazetapir (Marca et al., 2012). Injúrias e quedas na produção foram detectadas em milho, trigo, girassol e outras culturas quando foram semeados logo após a aplicação de imazetapir. Em batata e beterraba, essas injúrias foram observadas dois e três anos depois do plantio, respectivamente (Moyer \& Esau, 1996). 
Tabela 6 Resumo da análise de variância para estande, altura de plantas e produtividade de grãos em milho safrinha

\begin{tabular}{lccc}
\hline \multicolumn{1}{c}{ ANOVA } & Estande & Altura & Produtividade \\
\hline Valor de F & 0,87 & 2,11 & $2,46^{*}$ \\
C.V. $(\%)$ & 3,26 & 3,48 & 1,08 \\
E.P. & 0,05 & 0,59 & 35,78 \\
\hline CV: Coeficiente de variação. EP: & Erro padrão. \\
*Significativo a 5\% de probabilidade. &
\end{tabular}

O controle das plantas daninhas em áreas de sucessão de cultura visa remoção dos propágulos vegetativos e redução do banco de sementes em diferentes estágios de desenvolvimento (Gonçalves et al., 2013). Por este motivo o uso de herbicidas com efeito residual prolongado, como os testados neste trabalho, pode reduzir a competição imposta por plantas daninhas, bem como, serem seguros para a cultura do milho semeada em sucessão. O retorno da utilização de alguns princípios ativos em pré-emergência, especialmente aqueles herbicidas com efeito residual prolongado são alternativas viáveis ao controle de plantas daninhas, fazendo com que a seleção de biótipos resistentes seja desacelerada. Entretanto, é necessário que as ações sejam planejadas a fim de não colocar em risco a cultura de sucessão. Essa atenção é essencial uma vez que os sintomas de fitointoxicação podem não ser notados e, possivelmente, serão percebidos apenas na colheita, onde será constatado que a produtividade não respondeu ao investimento realizado. Apesar da literatura oferecer vários trabalhos nesta área, a maioria foi realizado nos Estados Unidos e na Europa, em condições bem diferentes das condições tropicais brasileiras, o que modifica muito o comportamento dos produtos no solo e a resposta da cultura do milho, quando em sucessão à soja.

Tabela 7 Valor médio de estande, altura de plantas e produtividade de grãos em milho safrinha

\begin{tabular}{|c|c|c|c|}
\hline Tratamentos* & Estande $^{1}$ & Altura $^{2}$ & Produtividade $^{3}$ \\
\hline Paraquate & $2,8 \pm 0,00$ & $33,3 \pm 0,50$ & $6.690,00 \pm 95,37 \mathrm{a}$ \\
\hline Clomazona + carfentrazona etílica & $2,9 \pm 0,12$ & $33 \pm 1,41$ & $6.661,50 \pm 66,16 \mathrm{a}$ \\
\hline Diclosulam & $2,8 \pm 0,00$ & $32,5 \pm 1,29$ & $6.688,50 \pm 100,08 \mathrm{a}$ \\
\hline S-metolacloro & $2,9 \pm 0,10$ & $34,5 \pm 1,29$ & $6.748,50 \pm 37,11 \mathrm{a}$ \\
\hline Trifluralina & $2,9 \pm 0,10$ & $33,3 \pm 0,96$ & $6.652,50 \pm 98,64 \mathrm{a}$ \\
\hline Imazetapir & $2,9 \pm 0,10$ & $33,8 \pm 0,96$ & $6.627,00 \pm 74,38 \mathrm{a}$ \\
\hline Sulfentrazona & $2,9 \pm 0,12$ & $34,8 \pm 1,26$ & $6.564,00 \pm 32,86 \mathrm{a}$ \\
\hline Imazetapir + flumioxazina & $2,8 \pm 0,00$ & $33,5 \pm 1,29$ & $6.673,50 \pm 51,70 a$ \\
\hline Flumioxazina & $2,9 \pm 0,12$ & $35 \pm 0,82$ & $6.586,50 \pm 55,07 \mathrm{a}$ \\
\hline
\end{tabular}

Médias seguidas pela mesma letra em coluna não diferem entre si pelo teste Scott-Knott, a 5\% de probabilidade. ${ }^{1}$ Plantas $^{-}$ ${ }^{2},{ }^{2} \mathrm{~cm},{ }^{3} \mathrm{Kg} \mathrm{ha}^{-1}$.

\section{Conclusão}

A mistura comercial de imazetapir + flumioxazina é eficaz tanto no controle de $D$. insularis quanto de espécies daninhas, monocotiledôneas ou eudicotiledôneas, cujo controle foi observado até os 35 DAA. Não houve residual dos tratamentos que prejudicasse a cultura do milho semeado após os 90 dias da aplicação dos herbicidas em pré-emergência.

\section{Agradecimentos}

Os autores gostariam de agradecer ao Instituto Federal Goiano, à FAPEG pela concessão da bolsa de estudos ao primeiro autor e ao Grupo Associado de Pesquisas do Sudoeste Goiano GAPES pelo apoio técnico nas realizações dos experimentos.

\section{Referências}

Abbott, W. S. A method of computing the effectiveness of on insecticide. Journal Economic Entomology, v. 18, n. 2, p. 265-267, 1925. https://doi.org/10.1093/jee/18.2.265a

Awan, T. H.; Sta Cruz, P. C.; Chauhan, B. S. Agronomic indices, growth, yield contributing traits, and yield of dry-seeded rice under varying herbicides. Field Crops Research, v. 177, p. 15-25, 2015. https://doi.org/10.1016/j.fcr.2015.03.001

Awan, T. H.; Sta Cruz, P. C.; Chauhan, B. S. Effect of pre-emergence herbicides and timing of soil saturation on the control of six major rice weeds and their phytotoxic effects on rice seedlings. Crop Protection, v. 83, p. 37-47, 2016. https://doi.org/10.1016/j.cropro.2016.01.013 
CABI: centre for agriculture and bioscience international. 2019. Invasive Species Compendium. Disponível em: < https://www.cabi.org/ISC/datasheet/109596\#56BD82BBA99F-4273-8EF1-DC6E5AFB60BE > Acessado em: 7 Jan 2019.

Canto-Dorow, T. S.; Longhi-Wagner, H. M. Novidades taxonômicas em Digitaria Haller (Poaceae) e novas citações para o gênero no Brasil. Insula, v. 30, p. 21-34, 2001. https://periodicos.ufsc.br/index.php/insula/article/viewFile /21616/19565

CONAB: Companhia nacional de abastecimento. Boletim anual de grãos. 2019. Disponível em: < https://www.conab.gov.br/info-agro/safras/graos >. Acessado em: 24 Maio 2019.

Dorn, B.; Stadler, M.; Van Der Heijden, M.; Streit, B. Regulation of cover crops and weeds using a roll-chopper for herbicide reduction in no-tillage winter wheat. Soil and Tillage Research, v. 134, p. 121-132, 2013. https://doi.org/10.1016/j.still.2013.07.014

Erasmo, E. A. L.; Pinheiro, L. L. A.; Costa, N. V. Phyto-sociological survey of weed communities in flooded rice areas cultivated under different management systems. Planta Daninha, v. 22, n. 26, p. 195-201, 2004. http://dx.doi.org/10.1590/S0100-83582004000200004

Gazola, T.; Belapart, D.; Castro, E. B.; Cipola Filho, M. L.; Dias, M. F. Características biológicas de Digitaria insularis que conferem sua resistência à herbicidas e opções de manejo. Científica, v. 44, n. 4, p. 557-567, 2016. http://dx.doi.org/10.15361/1984-5529.2016v44n4p557567

Gonçalves, J. L. M.; Alvares, C. A.; Higa, A. R.; Silva, L. D.; Alfenas, A. C.; Stahl, J.; Ferraz, S. F. B.; Lima, W. P.; Brancalion, P. H. S.; Hubner, A.; Bouillet, J. P. D.; Laclau, J. P.; Nouvellon, Y.; Epron, D. Integrating genetic and silvicultural strategies to minimize abiotic and biotic constraints in Brazilian eucalypt plantations. Forest Ecology and Management, v. 301, p. 6-27, 2013. https://doi.org/10.1016/j.foreco.2012.12.030

Han, H.; Vila-Aiub, M. M.; Jalaludin, A.; Yu, Q.; Powles, S. B. A double EPSPS gene mutation endowing glyphosate resistance shows a remarkably high resistance cost. Plant Cell Environment, v. 40, n. 12, p. 3031-3042, 2017. https://doi.org/10.1111/pce.13067

Heap, I. The international survey of herbicide resistant weeds. 2019. Disponível em: < www.weedscience.com >. Acesso em: 10 Jan 2019.

Marca, V.; Procopio, S. O.; Silva, G. A. da, Volf, G. Controle químico de milho voluntário resistente ao herbicida glyphosate. Revista Brasileira de Herbicidas, v. 14, n. 2, p. 103110, 2015. https://doi.org/10.7824/rbh.v14i2.408

Milanova, S.; Grigorov, P. Movement and persistence of imazaquin, oxyfluorfen, flurochloridone and terbacil in soil. Weed Research, v. 36, n. 1, p. 31-36, 1996. https://doi.org/10.1111/j.1365-3180.1996.tb01798.x

Moyer, J. R.; Esau, R. Imidazolinone herbicide effects on following rotational crops in Southern Alberta. Weed Technology, v. 10, n. 1, p. 100106 , https://doi.org/10.1017/S0890037X00045784

1996.

Muniz, D. R.; Garcia, J. S.; Braga, T. C.; Fátima, A.; Modolo, L.V. Pre-emergence application of (thio)urea analogues compromises the development of the weed species Bidens pilosa, Urochloa brizantha, and Urochloa decumbens. Journal of Advanced Research, v. 17, p. 95102, 2019. https://doi.org/10.1016/j.jare.2019.01.017

Pazuch, D., Trezzi, M. M., Guimarães, A. C. D., Barancelli, M. V. J., Pasini, R., Vidal, R. A. Evolution of Natural Resistance to Glyphosate in Morning Glory Populations. Planta Daninha, v. 35, p. 1-9, 2017. http://dx.doi.org/10.1590/s0100-83582017350100009

Pino, M. R., Muñiz, S., Val, J., Navarro, E. Phytotoxicity of 15 common pharmaceuticals on the germination of Lactuca sativa and photosynthesis of Chlamydomonas reinhardtii. Environmental Science and Pollution Research, v. 23, p. 22530-22541, 2016. http://dx.doi.org/10.1007/s11356-016-7446-y

Spadotto, C. A.; Marcondes, D. A. S.; Luiz, A. J. B.; Silvas, C. A. R. Determinação do período crítico para prevenção da interferência de plantas daninhas na cultura de soja: uso do modelo "broken-stick". Planta Daninha, v. 12, n. 2, p. 59-62, 1994. http://dx.doi.org/10.1590/S010083581994000200001 